\title{
Correlation between Atmospheric Temperature and Soil Temperature: A Case Study for Dhaka, Bangladesh
}

\author{
Khandaker Iftekharul Islam, Anisuzzaman Khan, Tanaz Islam \\ Department of Civil Engineering, IUBAT—International University of Business Agriculture and Technology, \\ Dhaka, Bangladesh \\ Email: iftikhar@alumni.chalmers.se
}

Received 15 April 2015; accepted 2 June 2015; published 5 June 2015

Copyright (C) 2015 by authors and Scientific Research Publishing Inc. This work is licensed under the Creative Commons Attribution International License (CC BY). http://creativecommons.org/licenses/by/4.0/

(c) (i) Open Access

\section{Abstract}

The main intention of this study was to substantiate the relation between atmospheric temperature and soil temperature within a system boundary. The study focused on coefficient of correlation that demonstrates the association between two variables. The earth surface temperature is anticipated to be affected by a set of meteorological parameters. Atmospheric temperature, humidity, precipitation and solar radiation directly influence the adjacent soil and the extent of impact must be varied at different part of the earth because of multiple factors. The primary step to validate the correlation was to collect two series of data for two variables i.e. atmospheric temperature and soil temperature of last ten years from 2003 to 2012. The coefficient of correlation was determined through Pearson's distribution whereas atmospheric temperature was considered as independent and soil temperature was dependent variable. The coefficients were calculated distinctly taking the soil temperature not only at several depths but also at separate faces of a day commensurate to overlying air temperature. The results indicated strong positive correlation up to $20 \mathrm{~cm}$ depth of soil which blatantly validates the premise of the study. The procedure was concluded with the regression analyses through which dependent variable (soil temperature) is projected corresponding to independent variable (air temperature). All possible coefficients of correlation were gathered in order to make the final comparison and analyses over the variation of magnitudes. Anomalies at which two variables are unable to continue linearity were portrayed in figures of the paper. Finally, influence graph is made to illustrate relative influence at different nominated depth of soil based on the coefficient of correlation.

\section{Keywords}

Statistical Correlation, Regression Analysis, Meteorology, Earth Science, Climate Data

How to cite this paper: Islam, K.I., Khan, A. and Islam, T. (2015) Correlation between Atmospheric Temperature and Soil Temperature: A Case Study for Dhaka, Bangladesh. Atmospheric and Climate Sciences, 5, 200-208. 


\section{Introduction}

The earth surface is anticipated to be affected by a set of meteorological parameters. The meteorological parameters include temperature, pressure, humidity, wind, precipitation, solar radiation etc. [1] which are interdependent to each other in terms of magnitude in the atmosphere. A number of attempts have been made in order to establish correlation among the different atmospheric parameters. Since then the curiosity has been grown up to determine the influence of climatic parameters on the surface of the earth. Atmospheric temperature, humidity, precipitation and solar radiation directly affect the adjacent soil [1] and the extent of effect must be varied with multiple factors existing at the different part of the earth that ultimately creates the scope to investigate the relation between soil and atmospheric temperature at a certain zone.

Soil surface temperature should correlate well with the temperature of air due to energy balance at the ground surface [2]. Soil temperature deems as a key climatic factor influencing ecosystem processes, specifically below the ground surface [3]. Soil temperature plays an important role in aiding decision making for many processes like soil respiration, crop production, pest growth, germination, pavement design etc. [4]. Moreover, the measuring process of soil temperature is very intricate, expensive and lengthy. Even it is too technical to install thermometer properly [4]. Even it is systematically painstaking to monitor soil temperatures for long period of time [3]. Therefore, to minimize the time and cost of measuring, this study is initiated.

The study will show at which extent atmospheric temperature is correlated to soil temperature and furthermore the prediction of soil temperature from existing overlying air temperature through a scientific process within a system boundary. The main intention of this study is to substantiate the association between atmospheric temperature and soil temperature at a certain zone. The outcome which is anticipated as strong correlation will be followed with an action to seek an equation by means of forecasting temperature of soil from the existing temperature of atmosphere through regression analysis.

\section{Study Area}

The study has been conducted for Dhaka division of Bangladesh which encompasses an area about 31,051 km². The tropical Dhaka division is wet and humid with a distinct monsoon where an annual average temperature is $25^{\circ} \mathrm{C}\left(77^{\circ} \mathrm{F}\right)$ [5]. In monsoon around $80 \%$ of the annual rainfall occurs which is almost 1483 millimeter while annual average precipitation is 1854 millimeters (73.0 in).

\section{Methodology}

The primary step to validate the correlation is to collect series of data for two variables i.e. atmospheric temperature and soil temperature of last ten years from 2003 to 2012. The coefficient of correlation is determined through Pearson's distribution whereas atmospheric temperature is considered as independent and soil temperature is dependent variable. This coefficient is a valid indicator of correlation between two variables based on statistical data. "Bangladesh Meteorological Department" is the source of these secondary data of two variables. The coefficients are calculated distinctly taking the soil temperature not only at several depths but also at separate faces of a day commensurate to air temperature. The procedure is concluded with the regression analyses which generate equations through which dependent variable (soil temperature) is projected corresponding to independent variable (air temperature). A table combines all coefficients of correlation for making final comparison and analyses over variation of the magnitudes. A graph entitled as "air and soil temperature vs. time" is plotted aiming at recognizing anomaly at which two variables are unable to continue linearity. An influence diagram is ultimately made to illustrate relative influence at different nominated depth of soil based on the coefficient of correlation.

\section{Result}

This study has performed an analysis speculating a correlation between soil and atmospheric temperature through which the interdependency would be demonstrated. Dhaka division has been considered as the system boundary and the correlation analysis conducted based on the secondary data which is sourced from BANGLADESH METEOROLOGICAL DEPARTMENT, DHAKA.

The sample was collected from several depths $(5,10,20 \& 30$ centimeter) at Dhaka station (BANGLADESH 
METEOROLOGICAL DEPARTMENT). And the temperature was measured 2 times in a day at 12.00 A.M. and 12 P.M. Atmospheric temperature (variable $\mathrm{x}$ ) from the same station and at the same time of a day is taken to correlate Soil temperature (variable y). So Sample size for the statistical correlation N $=7000=$ Days $\times$ Year + Leap year days - $153 \times 2$ (days-Aug to Dec, 2010)

[Meteorological Department could not record the data from Aug to Dec. in 2010 due to unavoidable technical problem]

$=\{365 \times 10(2003-2012)+3($ Leap year days in 2004, 2008, 2012) $-153 \times 2$

The correlation coefficient $r$ is calculated by Pearson's distribution, is the determinant through which the level of interdependency of two variables can be determined. At $5 \mathrm{~cm}$ depth of soil, the correlation coefficient $\mathrm{r}$ is 0.93 which has been calculated through Microsoft Excel, Where $\mathrm{N}=7000$ (Observation No.). In the same way, correlation coefficients are $0.93,0.87$, and 0.63 at the depth of 10,20 and $30 \mathrm{~cm}$ consecutively. The resulted coefficients indicate strong positive correlation up to $20 \mathrm{~cm}$ depth of soil which blatantly validates the premise of the study.

To experiment the result, few more analyses are conducted focusing on specific time of a day ranging the sample size accordingly. Two $\mathrm{r}$ values are calculated separately for night hour (12.00 a.m.) and day hour (12.00 p.m.) in order for the variation of result can be observed. Table 1 combines all coefficients of correlation (r) to observe the variation of the magnitudes below.

Since a strong correlation attained up to $20 \mathrm{~cm}$ through correlation analyses between the soil and atmospheric temperature in every individual case of sample size, hence regression analysis is conducted as further step [6].

Table 2 below represents the strength of correlation as per Dancey and Ready's (2004) categorization [7].

According to the study, the value of correlation coefficients are in a range of $0.7-0.9$ which implies a strong correlation [7] between the variables.

The general form of equation would be

$$
y=a+b x
$$

where, " $b$ " is the slope of the trend line and " $a$ " is the intercept of trend line with $Y$ axis.

In the regression analysis, Atmospheric temperature regards as independent variable $(x)$ whereas soil temp is the dependent variable $(y)$. A regression equation is generated running SPSS software in order to predict soil temperature.

Table 1. The values of correlation coefficient.

\begin{tabular}{cccc}
\hline Depth of soil $(\mathrm{cm})$ & $\mathrm{r}$ for $\mathrm{N}=7000$ & $\begin{array}{c}\mathrm{r} \text { for } \mathrm{N}=3500 \\
(12 \text { a.m. })\end{array}$ & $\begin{array}{c}\mathrm{r} \text { for } \mathrm{N}=3500 \\
(12 \mathrm{p} . \mathrm{m} .)\end{array}$ \\
\hline 5 & 0.93 & 0.93 & 0.89 \\
10 & 0.93 & 0.95 & 0.89 \\
20 & 0.87 & 0.93 & 0.87 \\
30 & 0.63 & 0.91 & 0.53 \\
\hline
\end{tabular}

Table 2. Classification of correlation.

\begin{tabular}{cc}
\hline Value of correlation coefficient & Strength of correlation \\
\hline & Perfect \\
$0.7-0.9$ & Strong \\
$0.4-0.6$ & Moderate \\
$0.1-0.3$ & Weak \\
0 & Zero \\
\hline
\end{tabular}




\subsection{Regression Summery of 2003-2012 at $5 \mathrm{~cm}$}

The first step of regression analysis is to generate a scatter plot for whole ten years data in order to demonstrate the linearity between soil and atmospheric temperature. The following scatter plot of Figure 1 validates a significant linearity between the two variables for $5 \mathrm{~cm}$ depth.

The linear relationship between variables leads to further progress in analysis and eventually SPSS software produced Table 3 with features against ten years of data at $5 \mathrm{~cm}$ depth through regression analysis.

The equitation from regression analysis:

$$
y=3.83+0.9 x
$$

\subsection{Regression Summery of 2003-2012 at $10 \mathrm{~cm}$}

Similarly, both Figure 2 and Table 4 confirm considerable linearity between soil and air temperature for soil at $10 \mathrm{~cm}$ depth.

Constant a (Intercept) $=6.224$ and $\mathrm{b}=0.842$ (Slope)

Generated Equation: $y=6.224+0.842 x$

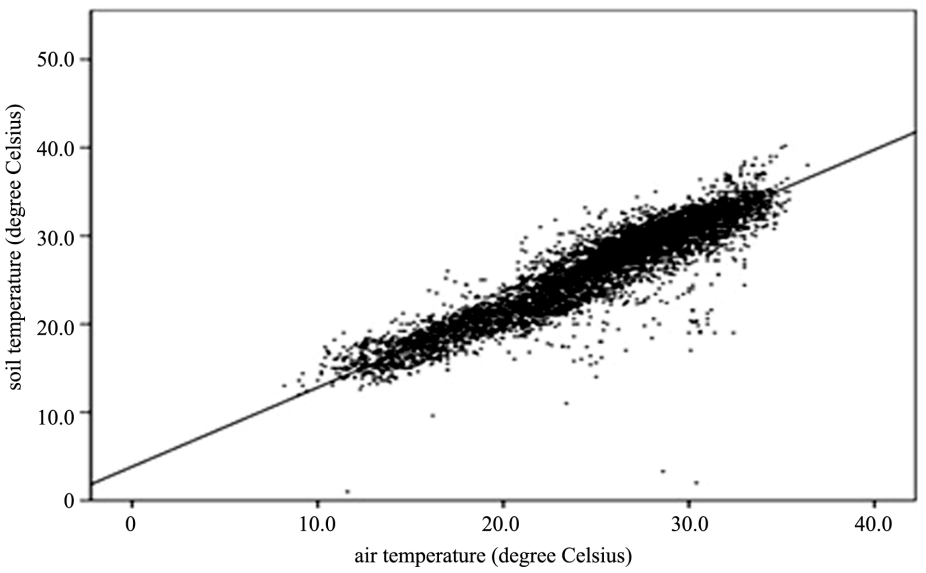

Figure 1. Scatter Plot for $5 \mathrm{~cm}$ depth.

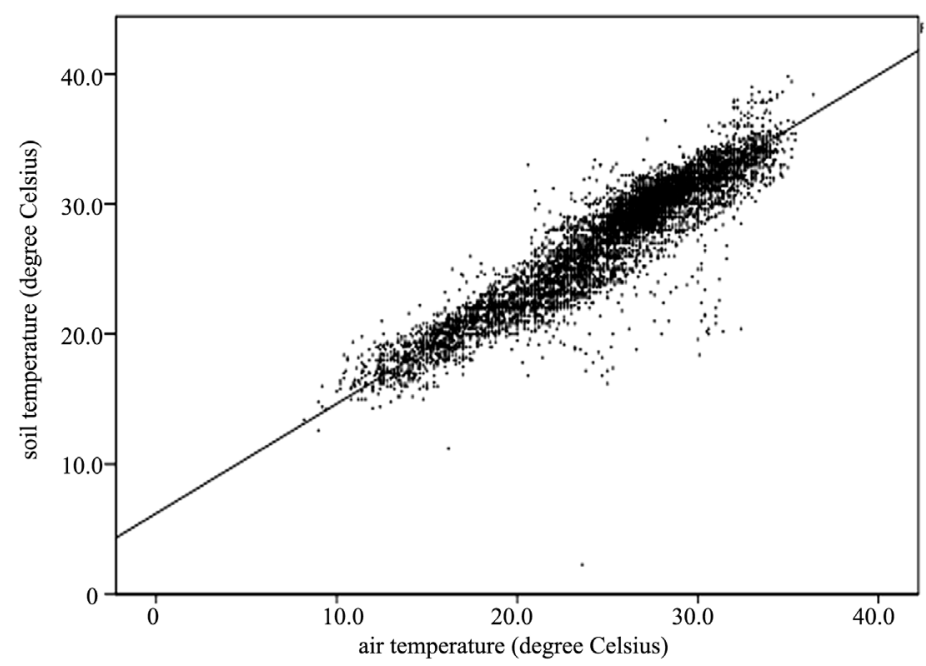

Figure 2. Scatter Plot for $10 \mathrm{~cm}$ depth. 


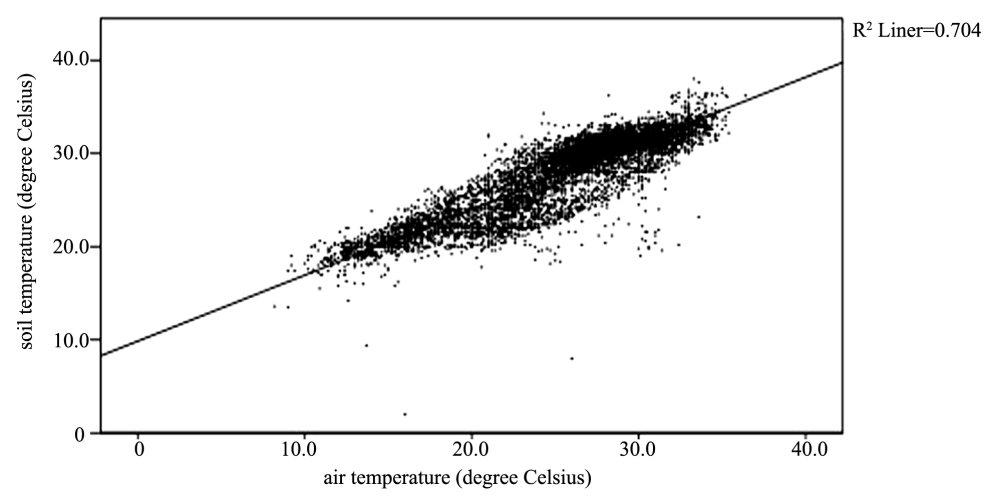

Figure 3. Scatter Plot for $20 \mathrm{~cm}$ depth.

Table 3. Regression summery for $5 \mathrm{~cm}$.

\begin{tabular}{|c|c|c|c|c|c|c|c|c|}
\hline & \multirow{2}{*}{ Model } & \multicolumn{2}{|c|}{ Unstandardized Coefficients } & \multirow{2}{*}{$\begin{array}{c}\text { Standardized } \\
\text { Coefficients }\end{array}$} & \multirow{2}{*}{$\mathrm{t}$} & \multirow{2}{*}{ Sig. } & \multicolumn{2}{|c|}{$\begin{array}{l}\text { 95.0\% Confidence } \\
\text { Interval for B }\end{array}$} \\
\hline & & B & Std. Error & & & & $\begin{array}{l}\text { Lower } \\
\text { Bound }\end{array}$ & Upper Bound \\
\hline \multirow[b]{2}{*}{1} & (Constant) & 3.830 & 0.115 & & 33.244 & 0.000 & 3.604 & 4.055 \\
\hline & $\begin{array}{l}\text { Air temperature } \\
\text { (degree Celsius) }\end{array}$ & 0.898 & 0.004 & 0.923 & 201.197 & 0.000 & 0.890 & 0.907 \\
\hline
\end{tabular}

Constant $\mathrm{a}($ Intercept $)=3.83$ and $\mathrm{b}=0.898$ (Slope) .

Table 4. Regression summery for $10 \mathrm{~cm}$.

\begin{tabular}{|c|c|c|c|c|c|c|c|c|}
\hline & \multirow{2}{*}{ Model } & \multicolumn{2}{|c|}{ Unstandardized Coefficients } & \multirow{2}{*}{$\begin{array}{c}\text { Standardized } \\
\text { Coefficients } \\
\text { Beta }\end{array}$} & \multirow{2}{*}{$\mathrm{t}$} & \multirow{2}{*}{ Sig. } & \multicolumn{2}{|c|}{$\begin{array}{l}\text { 95.0\% Confidence Interval } \\
\text { for B }\end{array}$} \\
\hline & & B & Std. Error & & & & Lower Bound & Upper Bound \\
\hline \multirow[b]{2}{*}{1} & (Constant) & 6.224 & 0.106 & & 58.733 & 0.000 & 6.016 & 6.432 \\
\hline & $\begin{array}{c}\text { air temperature } \\
\text { (degree Celsius) }\end{array}$ & 0.842 & 0.004 & 0.929 & 204.555 & 0.000 & 0.834 & 0.850 \\
\hline
\end{tabular}

Table 5. Regression summery for $20 \mathrm{~cm}$.

\begin{tabular}{|c|c|c|c|c|c|c|c|c|}
\hline & \multirow{2}{*}{ Model } & \multicolumn{2}{|c|}{ Unstandardized Coefficients } & \multirow{2}{*}{$\begin{array}{c}\text { Standardized } \\
\text { Coefficients } \\
\text { Beta }\end{array}$} & \multirow{2}{*}{$\mathrm{t}$} & \multirow{2}{*}{ Sig. } & \multicolumn{2}{|c|}{ 95.0\% Confidence Interval for B } \\
\hline & & B & Std. Error & & & & Lower Bound & Upper Bound \\
\hline \multirow[b]{2}{*}{1} & (Constant) & 9.871 & 0.124 & & 79.760 & 0.000 & 9.629 & 10.114 \\
\hline & $\begin{array}{c}\text { air temperature } \\
\text { (degree Celsius) }\end{array}$ & 0.708 & 0.005 & 0.874 & 147.151 & 0.000 & 0.698 & 0.717 \\
\hline
\end{tabular}

\subsection{Regression Summery of 2003-2012 at $20 \mathrm{~cm}$}

Figure 3 as well as Table 5 also demonstrates substantial linear relation between the variables at $20 \mathrm{~cm}$ depth of soil.

The equation from regression analysis: $y=9.871+0.708 x(4)$. All the equations are accumulated here according to depth in Table 6.

\section{Analysis}

Rainfall realistically minimizes the temperature of air and soil for a certain while on a day within the zone. This is because the temperature of water droplets is supposed to be less than the air and soil particles of the subjected region. But once the temperature regain rapidly in atmosphere, saturated soil laps more long in raising its tem- 
Table 6. A list of regression equation at different depth.

\begin{tabular}{cc}
\hline Depth (cm) & Equation \\
\hline 5 & $y=3.83+0.9 x$ \\
10 & $y=6.224+0.842 x$ \\
20 & $y=9.871+.708 x$ \\
\hline
\end{tabular}

perature. Some extreme weather conditions which include depression, heavy rainfall, etc. may cause a sharp drop of atmospheric temperature. But these fluctuations were not being reflected accordingly at that extent in soil temperature (i.e. $352^{\text {th }}$ day on "Soil and Air temperature vs. Time" curve for 2008) due to thermal conductivityfactor. However, thermal conductivity of saturated soil is greater than dry soil, but saturated soil evaporates water to the atmosphere before warming up [8]. So, the saturated soil is being unable to follow the linearity with the atmosphere as like dry soil do. This anomaly contributes pulling down the magnitudes of coefficient of correlation from ideal correlation value 1.

On the other hand, sunlight energy stimulates soil particles and in consequence of stimulation temperature of earth rises. But in cloudy weather, this energy transfer from the sun is interrupted. Cloud which is characterized by neutral thermal conductivity [9] not only inhibits energy transfer from the sun but also restrain released energy from the earth in the atmosphere [9]. That's why, for the long run, atmospheric temperature increase whereas soil temperature is lagged behind. These phenomena delineate the causes of variance of statistical data in establishing the linearity. The following curve noticeably depicts the linearity features of atmospheric temperatures and soil temperatures although aberrant are noticed. Daily average soil and air temperatures are plotted against time for 2008, 2009 and 2010 (Jan to July) in Figures 4-6 respectively.

Finally, Figure 7 is produced combining those three curves from January, 2008 to July, 2010.

Soil temperature fluctuates throughout the year with the incident of solar radiation, rainfall, seasonal swing of overlying air temperature and with the depth of the earth. However, the soil temperature at the depth below 10 meter remains relatively constant all the year round [10]. Figure 8 is the influence graph which shows relative influence based on correlation coefficient's values at different depth of soil.

That infers soils at deeper level experience declining influence than the soils at shallower depth for overlying air temperature. This is because; vegetation covers and surface layers provide thermal insulation above deeper soil [10].

As correlation coefficient indicates strong correlation between daily average air and soil temperature, nevertheless few shortcomings are identified in performing the analysis. Soil and air temperatures were taken twice in a day at twelve hours interval to correlate and average soil and air temperature is taken to plot the graph 'daily average soil and atmospheric temperature vs. time' for the sake of determining seasonal anomalies and extremes. If the atmospheric temperature and soil temperature could be taken simultaneously a number of times within a day to run the correlation analysis, then the result would be more accurate and it would be feasible to recognize the anomalies and extremes more precisely.

\section{Discussion}

In order to predict daily soil temperature from air temperature, equations are established through regression analysis for a particular type of climate like Dhaka Division. As Bangladesh is not a diverse climatic region, that's why this equation can cover the whole area of Bangladesh with the inclusion of similar climatic areas around the world. The developed equation which is recommended to predict daily soil temperature at different depth from overlying air temperature is reasonably effective at a large scale. Instead of large scale, if it requires location-based application to attaining more precision, regression equation can be modified in accordance with the data of that concerned area. The outcome of this study would contribute in Meteorological, Ecological, Agricultural and Geological divisions within a certain system boundary. The study is important for geological researches. This is because the soil temperature has a significant role in soil formation as a geological process. Even this will facilitate the Agricultural Department for making decision in selecting appropriate sites and crops to be cultivated there. Soil temperature determines ecological diversity in soil. Bangladesh Meteorological Department is supposed to measure soil temperature on a regular basis; the application of the regression equation 


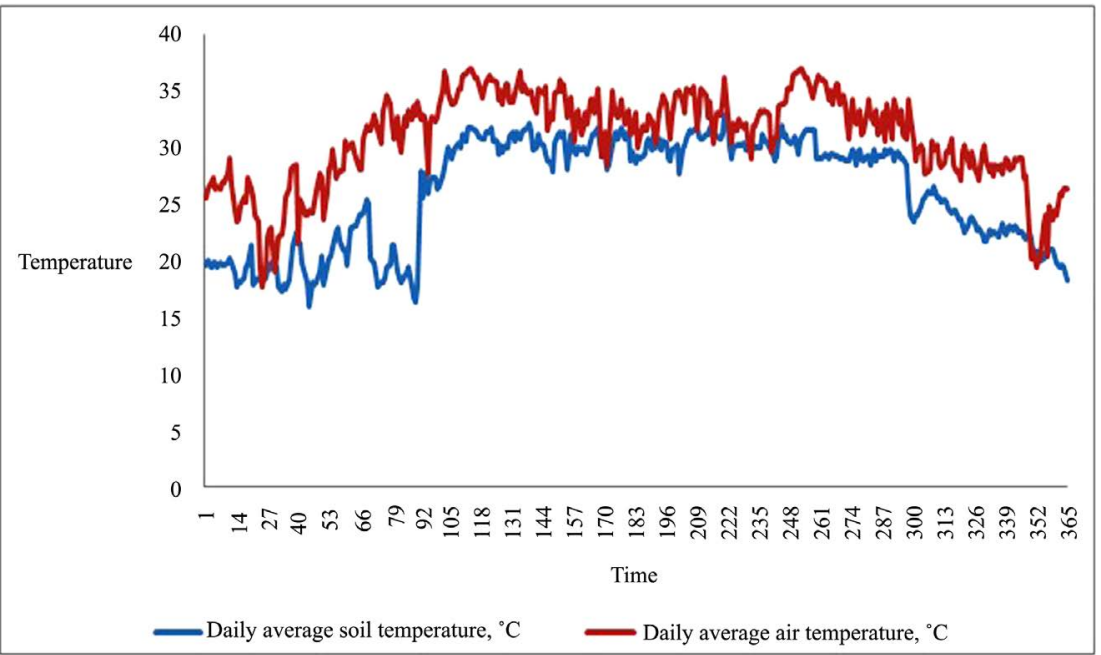

Figure 4. Soil and Air temperature vs. Time (For 2008).

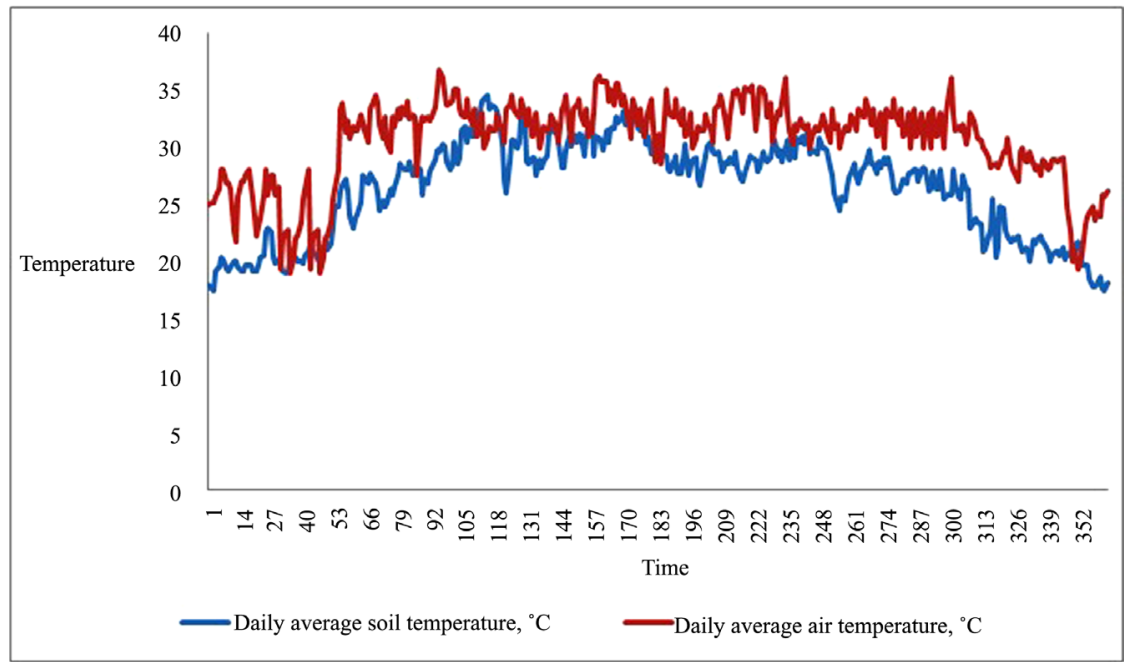

Figure 5. Soil and Air temperature vs. Time (For 2009).

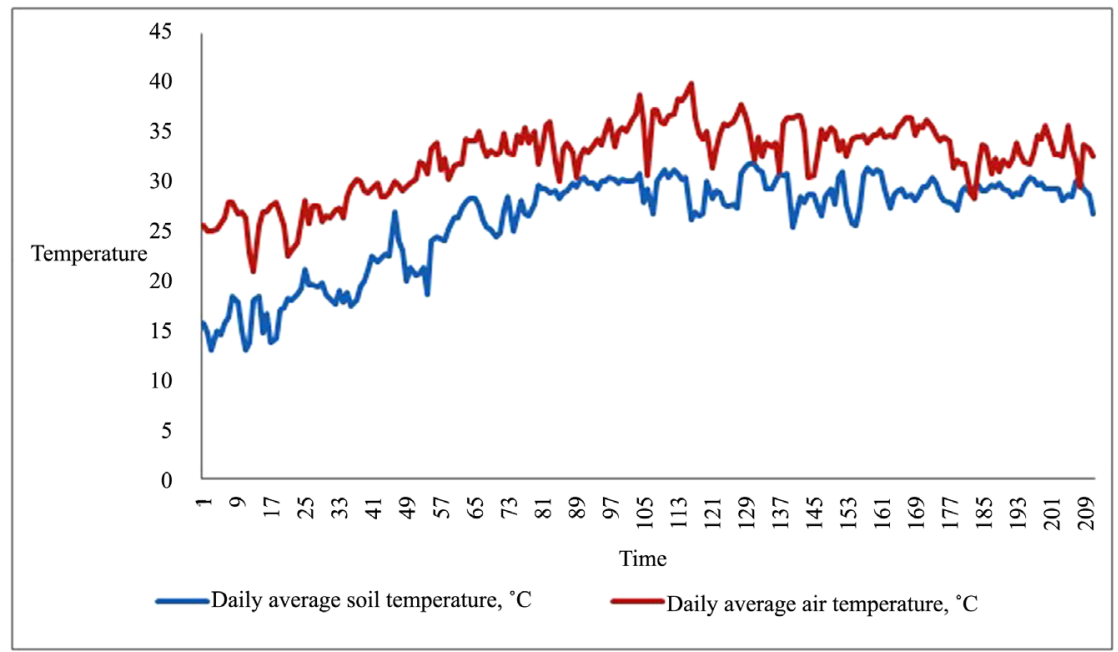

Figure 6. Soil and Air temperature vs. Time (For 2010). 


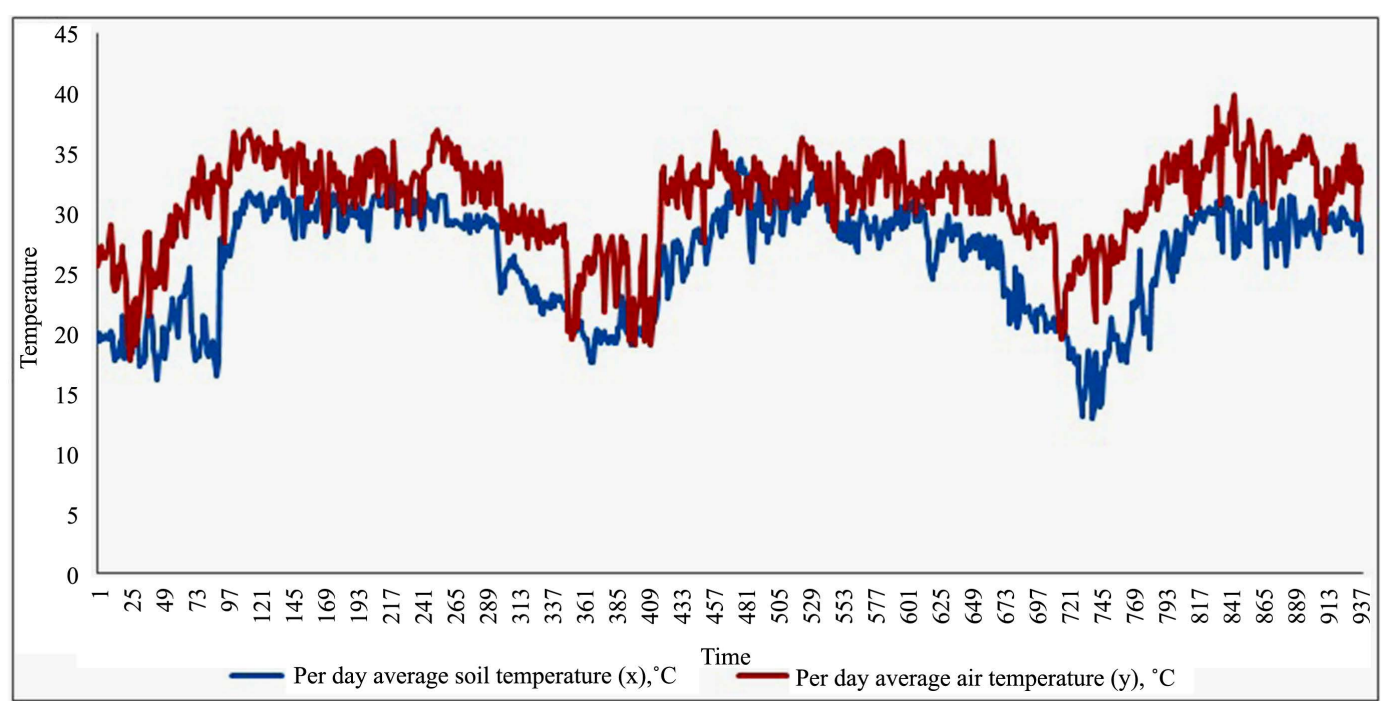

Figure 7. Soil and Air temperature vs. Time (2008-2010).

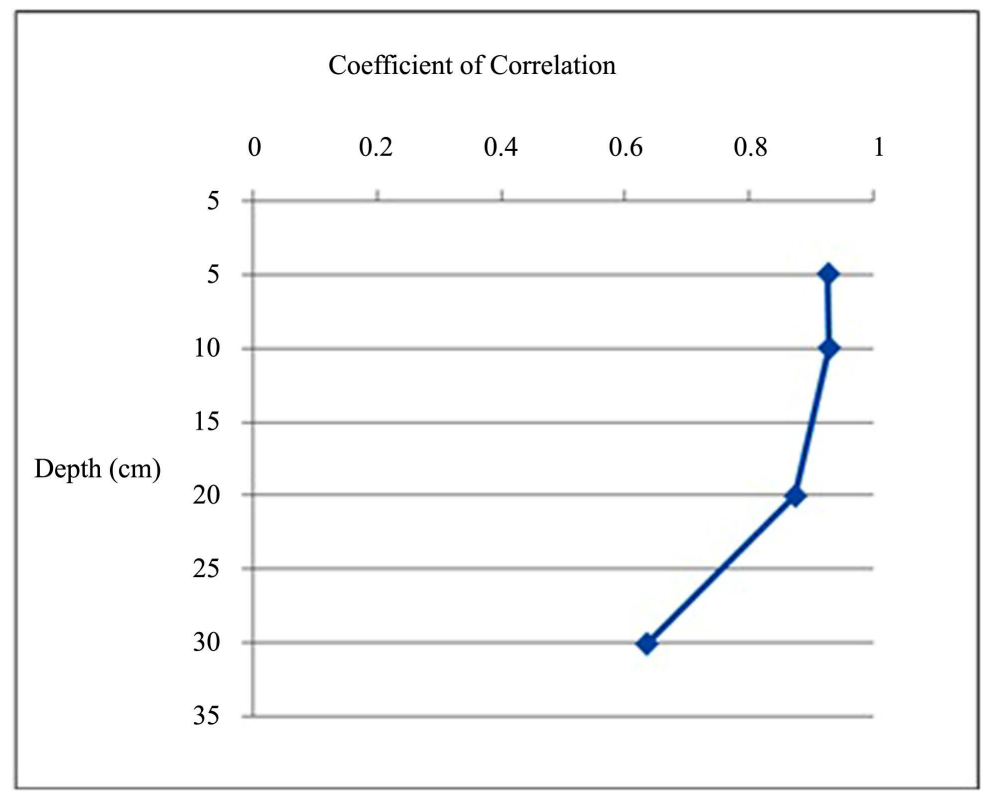

Figure 8. Influence graph (Depth vs. Coefficient of correlation).

will eliminate the use of tedious and time consuming method of measuring soil temperature. So, it ultimately leads in saving the time and money. Here just air temperature will be required as an input to get the output in the form of soil temperature.

\section{Acknowledgements}

We want to acknowledge Bangladesh Meteorological Department, Dhaka for providing us the valuable data of atmospheric and soil temperature. So, we present our gratitude and special thanks to B.M.D. for their contribution.

\section{References}

[1] FAO Document Repository (1998) Natural Resource Management and Environment Department, Chapter 3-Meteorological Data. http://www.fao.org/docrep/x0490e/x0490e07.htm\#meteorological\%20factors\%20determining\%20et 
[2] Zheng, D., Hunt, E.R. and Running, S.W. (1993) A Daily Soil Temperature Model Based on Air Temperature and Precipitation for Continental Applications. Climate Research, 2, 183-191. http://dx.doi.org/10.3354/cr002183

[3] Brown, S.E., Pregitzer, K.S., Reed, D.D. and Burton, A.J. (2000) Predicting Daily Mean Soil Temperature from Daily Mean Air Temperature in Four Northern Hardwood Forest Stands. Forest Science, 46, 297-301.

[4] Ahmad, M.F. and Rasul, D.G. (2008) Prediction of Soil Temperature by Air Temperature: A Case Study for Faisalabad. Pakistan Journal of Meteorology, 5, 19-27.

[5] Koppen, W. (1923) Dle Klirnate der Erde. Walter de Gruyter, Berlin.

[6] Schwarz, C.J. (2013) Sampling, Regression, Experimental Design and Analysis for Environmental Scientists, Biologists, and Resource Managers, Department of Statistics and Actuarial Science, Simon Fraser University, Viewed 6 August, 2014. http://people.stat.sfu.ca/ cschwarz/Stat-650/Notes/PDFbigbook-JMP/JMP-part016.pdf

[7] Dancey, C. and Reidy, J. (2004) Statistics without Maths for Psychology: using SPSS for Windows. Prentice Hall, London.

[8] Newton and Ask a Scientist 2012, Soil Moisture Content. http://www.newton.dep.anl.gov/askasci/wea00/wea00105.htm

[9] Newton and Ask a Scientist 2012, Length of Daylight and Temperature. http://www.newton.dep.anl.gov/askasci/wea00/wea00105.htm

[10] Build It Solar, 2005, Ground Temperatures as a Function of Location, Season, and Depth. http://www.builditsolar.com/Projects/Cooling/EarthTemperatures.htm. 